\title{
Multiband Microstrip Patch Antenna for 5G Wireless Communication
}

\author{
Waqar Hussain ${ }^{1}$, M.irfan Khattak ${ }^{2}$, Mushtaq A.K.Khattak ${ }^{3}$, Muhammad Anab \\ $1,2,3,4$ \\ UET Peshawar, Pakistan \\ w.hussain@uetpeshawar.edu.pk ${ }^{1}$ \\ Received: 05 August ${ }^{2019}$, Revised: 20 October $^{2019}$, Accepted: 06 January
}

\begin{abstract}
In current time's an immense proliferation occurred in the user's density of wireless communication, not so far but in near past one channel was enough for the necessities of a single mobile user. Now even $4 \mathrm{G}$ technology is inadequate to deliver its clienteles a wider bandwidth, gain and fast communication. For need of high hasten communication technology alteration is under way and is switching from $4 \mathrm{G}$ to 5G. For multi-channel communication necessity, communicating gadgets are integrated with multiple bands having peculiarity to work on disparate frequency channels in a single device. In this projected work microstrip patch antenna is used as communicating tool and analyzed for one band and dual band communication at higher frequencies (mm-waves). Microstrip patch antenna is selected because of its simple design, low price, compactness and compatibility with circuit elements. A dual band U-shaped slotted Microstrip patch antenna with $28 \mathrm{GHz}$ and $38 \mathrm{GHz}$ operating bands is presented in this paper. The total area of antenna is $8.5 \times 8 \times 0.254 \mathrm{~mm}^{3}$, the substrate used in designing is Rogers RT 5880 having a dielectric constant 2.2. The antenna resulted in return loss of $32 \mathrm{~dB}$ at $28 \mathrm{GHz}$ and $-40 \mathrm{~dB}$ at $38 \mathrm{GHz}$. The simulated gain of proposed dual band is $6.7 \mathrm{~dB}$ at $28 \mathrm{GHz}$ and $7.92 \mathrm{~dB}$ at $38 \mathrm{GHz}$.
\end{abstract}

Keywords - MPA, Microstrip antenna array, 5G, mm-waves, Return Loss.

\section{INTRODUCTION}

The user density is increasing day by day there is a big difference between the current density of users now and a few years ago after each year a large number of new users get access to the channel, therefore there is a prominent development in the arena of wireless technology, As the user density is aggregate similarly higher data rates and wide bandwidth increase the importance to accommodate that massive user density, it is indispensable to provide them multiple channels so that they can get uninterrupted service, in current era the field of $5 \mathrm{G}$ is emerging, now communication will takes place on higher frequencies (mm-band), therefore to allot the users high data rates various techniques are used linked with antenna to meet the requirements of higher number of users, for this purpose multiband antennas are usually used with diverse optimization approaches like using of array, slot or MIMO approach in recent era MIMO approach plays an gigantic role in providing higher emitted efficiency of the emitted EM waves both in near and far field regions and the data rate is quite high, both in $4 \mathrm{G}$ and now in $5 \mathrm{G}$. when you have to provide access to multiusers at a time you will need a vast quantity of broad casting devices on both side via transmitter or receiver [1], by proper enactment of Slot, MIMO or Array approach, there is an extreme development in data rate, user allotting and handling aptitude. The $\mathrm{mm}$ frequency bands at the present time are under consideration around the globe because it is the probable sturdy entrant for meeting the congested user density [2]. Research is proceeding on the $\mathrm{mm}$ bands that come under the umbrella of $5 \mathrm{G}$, these mm frequencies ensembles are comprised of $28 \mathrm{GHZ}$, $38 \mathrm{GHZ}, 60 \mathrm{GhHZ}$ some even work on more than $70 \mathrm{GHz}$. In broadcasting devices antenna act as imperative player in wireless system. The radiated waves usually in $\mathrm{mm}$ bands agonize after atmospheric fascination, it include the issue of path loss also. Therefore the manufacturing and outline of an antenna has two main concerns, first a high gain and second a covenant size which is nothing more than a challenge. Bandwidth amplification and dimensions detraction are appropriate prevailing design politeness for the pragmatic consumption of MPA [4], it is indispensable for an antenna element to have a low profile dimension, low budget, to have the peculiarity to work on distinct $\mathrm{mm}$ bands. Enormous research considerations have been adopted with multiband antenna devices that utilize the $\mathrm{mm}$ bands [5]. A profound number of designs employed on $\mathrm{mm}$ bands are addressed in today era and are appropriate for 5G [5], the architecture of a circular geometrical alignment of MPA is illustrated in [6] with a slot acquainted in patch operating at $28 \mathrm{GHz}$, one MIMO outline which is investigated in [7] works on three dissimilar bands. This design is composed of $2 \mathrm{D}$ antenna having an introduced slot designed for $28 \mathrm{GHz}$ band. In [8] an MPA antenna has been depicted with multiband peculiarity and used slot technique for $2 \times 4$ MIMO attaining of multiband characteristics, the projected design is set up above the dielectric material made of FR4 having $\mathbf{k}=4.2 \& 1.6 \mathrm{~mm}$ thickness, it resonates at $7.4 \mathrm{GHz}$ possess a $308 \mathrm{MHz}$ bandwidth along with $9.68 \mathrm{GHz}, 12.04 \mathrm{GHz} \& 12.86 \mathrm{GHz}$ under the stag frequency range of $4.8 \mathrm{GHz}$. The antenna has return loss of $-21.45 \mathrm{~dB},-33.51 \mathrm{~dB},-16.48 \mathrm{~dB}$ and $-10.78 \mathrm{~dB}$ at operating frequencies. For gain enhancement researches are 
focusing on antenna arrays like one illustrated in [9] in which MPA (parasitic) comprised of 42-elements is capable of working on mm-wave frequencies, antenna provides $6.3 \%$ FBW and 1.96 VSWR for frequencies varying from 26.83$28.56 \mathrm{GHz}$. Antennas intended for $5 \mathrm{G}$ technology is projected to be minor in size with elevated gain as compared to others that are utilized for both $3 \mathrm{G}, 4 \mathrm{G}$ networks. $5 \mathrm{G}$ antennas require extra

innovative steering and scanning approaches with the aim to act adequately. It offers the likelihood possession of extended channel frequency extent conceivably varying from 1 to $2 \mathrm{GHz}$, a 4 element double band printed antenna array with slots formation for $5 \mathrm{G}$ is depicted that offers an adequate impedance matching at 28/38 which are sought bands in mm waves, |S11| is lower than $-10 \mathrm{~dB}$, having $10.58 \mathrm{~dB}$ gain at $28 \mathrm{GHz}$ and 12.15 $\mathrm{dB}$ at $38 \mathrm{GHz}$ [10]. Numerous configurations are delineated in [11] and [12] for bandwidth augmentation, for instance enlarging the thickness of dielectric material (substrate), usage of a small truncated substrate, the adoption of miscellaneous tactics for impedance equivalency and patch invigorating, the adoption of diversified resonators [13], use of aperture coupling fed technique in [14], the utilization of slot antenna for gain melioration [15] or acquainting of thickened parasitic patch substrate [16].

A dual band U-shaped slotted Microstrip patch antenna is designed for $5 \mathrm{G}$ technology with $28 \mathrm{GHz}$ and $38 \mathrm{GHz}$ as operating bands. In first phase of designing a single band Microstrip patch antenna with Rogers RT 5880 substrate and 2.2 dielectric constant was designed and analyzed for $28 \mathrm{GHz}$ band, substrate has $8 \times 8.5 \mathrm{~mm}^{2}$ dimeniosn with $0.254 \mathrm{~mm}$ hight.The single band is fed by inset fed line approach, the projected single band antenna has a return loss of $-48 \mathrm{~dB}$ at $28 \mathrm{GHz}$ and VSWR less than 2. For attaining the multiband features two U-shaped slots were introduced in patch design, two distinct bands of $28 \mathrm{GHz}$ and $38 \mathrm{G}$ were attained with the help of these inserted slots, the proposed dual band slotted microstrip patch antenna has gain of $6.7 \mathrm{~dB}$ at $28 \mathrm{GHz}$ and $7.92 \mathrm{~dB}$ at $38 \mathrm{GHz}$ respectively. The dual band has a return loss of $-32 \mathrm{~dB}$ at $28 \mathrm{GHz}$ and $-40 \mathrm{~dB}$ at $38 \mathrm{GHz}$ band.

\section{DESIGN OF SINGLE BAND MicRostriP PATCH ANTENNA}

The substrate used in design of single band MPA antenna is Rogers RT 5880 having $\varepsilon_{r}=2.2$ and $8 \times 8.5 \times$ $0.254 \mathrm{~mm}^{3}$ dimensions, total area of radiating patch is $3.27 \times$ $4.09 \times 0.035 \mathrm{~mm}^{3}$. For excitation of patch inset feed approach is used. The designed single band antenna is analyzed at $28 \mathrm{GHz}$ frequency. The parameters used for designing of said antenna is projected in table 1 .

TABLE I DESIGNING PARAMETERS OF SINGLE BAND MPA

\begin{tabular}{|c|c|c|}
\hline Description & Values & Parameter \\
\hline Substrate length & $8 \mathrm{~mm}$ & $L_{s}$ \\
\hline Substrate width & $8.5 \mathrm{~mm}$ & $W_{s}$ \\
\hline Substrate height & $0.254 \mathrm{~mm}$ & $h_{s}$ \\
\hline Patch length & $3.27 \mathrm{~mm}$ & $L_{p}$ \\
\hline
\end{tabular}

\begin{tabular}{|l|l|c|}
\hline Patch width & $4.09 \mathrm{~mm}$ & $W_{p}$ \\
\hline Feedline length & $3.12 \mathrm{~mm}$ & $L_{f}$ \\
\hline Feedline width & $0.782 \mathrm{~mm}$ & $W_{f}$ \\
\hline
\end{tabular}

The width of inset feedline cut is $0.411 \mathrm{~mm}$. The listed mathematical equations were used in calculating the dimensions of designed single band MPA like equation (1) for width calculation, equation (2) for calculation of effective length, equation (3) for factual length, and (4) for determination of feedline width

$$
\begin{gathered}
w=\frac{c}{2 f_{r} \sqrt{\frac{e r+1}{2}}} \ldots . \\
L_{e f f}=\frac{c}{2 f_{r} \sqrt{\varepsilon_{r e f f}}} . \\
L=L_{e f f}-2 \Delta L \ldots \\
w_{f}=\left(\frac{377}{z_{o} \sqrt{\varepsilon_{r}}}\right) h \ldots .
\end{gathered}
$$

The front and perspective view of designed Microstrip patch antenna is delineated in figure 1

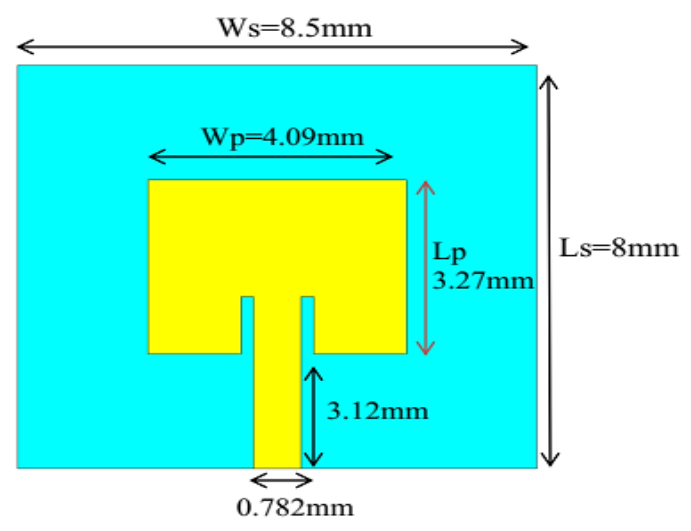

(a)Front view

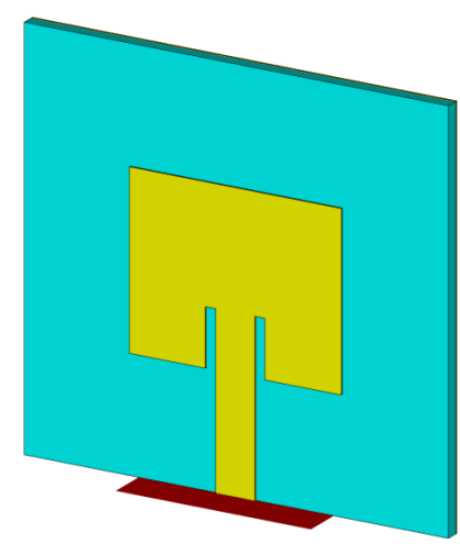

(b)Perspective View

Figure 1: Front and perspective view of designed single band MPA is delineated 
After simulation at $28 \mathrm{GHz}$ operating frequency the designed single band MPA resulted with return loss of $-48 \mathrm{~dB}$ and voltage standing wave ratio in between 1 and 2 . The simulated results for both S11 and VSWR are delineated in figure 2 and 3 respectively

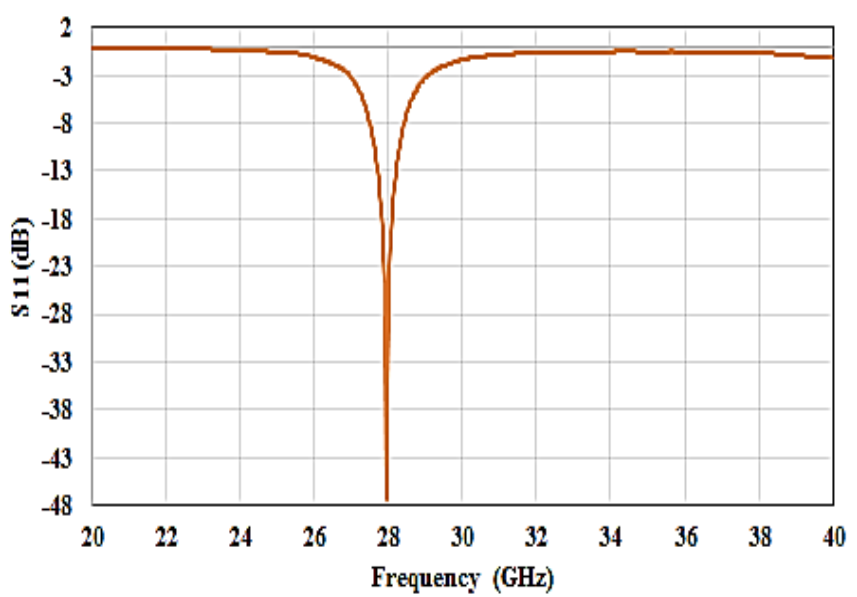

Figure 2: S11 of single band MPA at $28 \mathrm{GHz}$ frequency

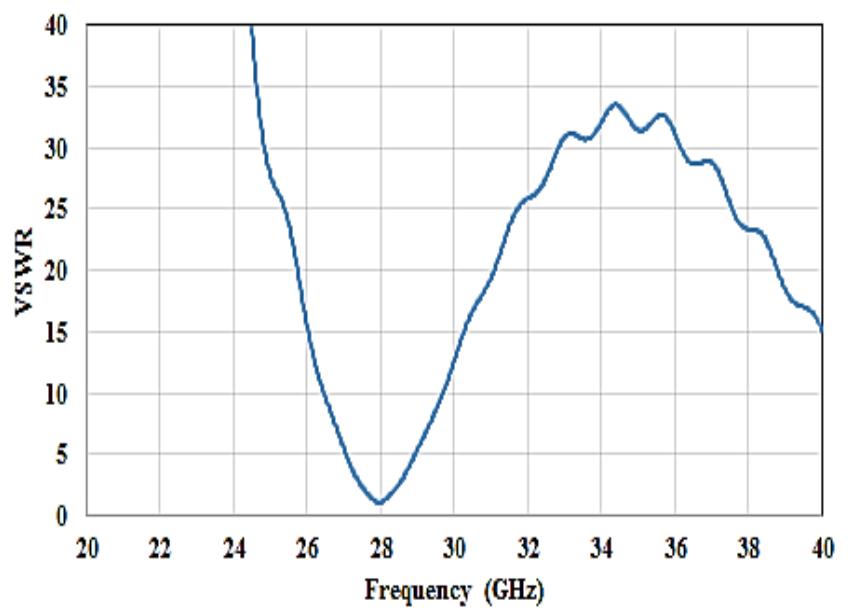

Figure 3: VSWR of single band MPA at $28 \mathrm{GHz}$ frequency

\section{INSERTION OF U-SHAPED SLOTS IN PATCH}

Owing to addition of two U-shaped slots in patch of prior designed single band MPA, an additional $38 \mathrm{GHz}$ band was attained. Due to the insertion of slots the proposed antenna got multiband characteristics. The substrate used in designing of proposed dual band antenna is of Rogers RT 5880 with epsilon 2.2. Total area of the proposed antenna is $8 \times 8.5 \times$ $0.254 \mathrm{~mm}^{3}$.An inset feedline of $50 \Omega$ is provided to patch. Designing parameters of substrate, patch, feedline and slots along with description are delineated in table 2 .
TABLE II DESIGNING PARAMETERS OF PROPOSED DUAL BAND SLOTTED MPA

\begin{tabular}{|c|l|l|}
\hline \multicolumn{1}{|c|}{ Parameters } & \multicolumn{1}{|c|}{ Values } & \multicolumn{1}{c|}{ Description } \\
\hline$L_{S}$ & $8 \mathrm{~mm}$ & Length of substrate \\
\hline$W_{s}$ & $8.5 \mathrm{~mm}$ & Width of substrate \\
\hline$L_{p}$ & $3.27 \mathrm{~mm}$ & Length of patch \\
\hline$W_{p}$ & $4.09 \mathrm{~mm}$ & Width of patch \\
\hline$L_{f}$ & $3.12 \mathrm{~mm}$ & Length of feedline \\
\hline$W_{f}$ & $0.782 \mathrm{~mm}$ & Width of feedline \\
\hline $\mathrm{H}$ & $0.254 \mathrm{~mm}$ & Height of substrate \\
\hline $\mathrm{Mt}$ & $0.035 \mathrm{~mm}$ & Thickness of patch \\
\hline $\mathrm{Wc}$ & $0.411 \mathrm{~mm}$ & Width of inset feed cut \\
\hline $\mathrm{W} 1$ & $1.6 \mathrm{~mm}$ & Slot width \\
\hline $\mathrm{L} 1$ & $1.20 \mathrm{~mm}$ & Slot length \\
\hline Mx & $0.2 \mathrm{~mm}$ & $\begin{array}{l}\text { Space between two } \\
\text { slots }\end{array}$ \\
\hline $\mathrm{D} 1$ & $0.245 \mathrm{~mm}$ & $\begin{array}{l}\text { Distance between } \\
\text { patch and slot length }\end{array}$ \\
\hline $\mathrm{D} 2$ & $0.37 \mathrm{~mm}$ & $\begin{array}{l}\text { Distance between } \\
\text { patch and slot width }\end{array}$ \\
\hline $\mathrm{T} 1$ & $0.2 \mathrm{~mm}$ & Slot thickness \\
\hline
\end{tabular}

The front and perspective view of proposed dual band MPA antenna is depicted in figure 4 ( $\mathrm{a}$ and $\mathrm{b}$ ).

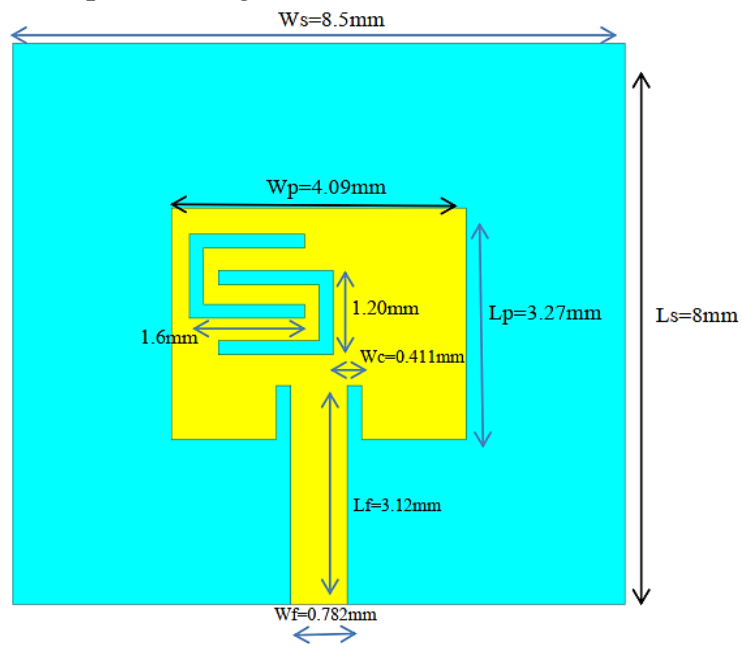

(a)Front view

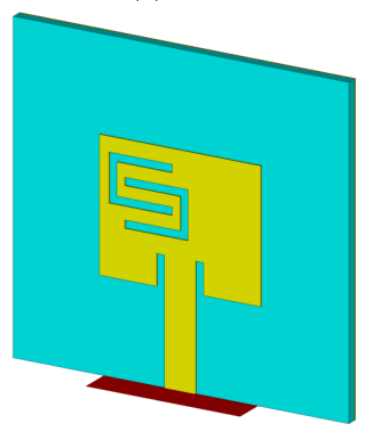

(b) perspective View

Figure 4: Front and perspective view of proposed dual band MPA antenna 
The labeled structure of slots introduced in patch is delineated in figure 5

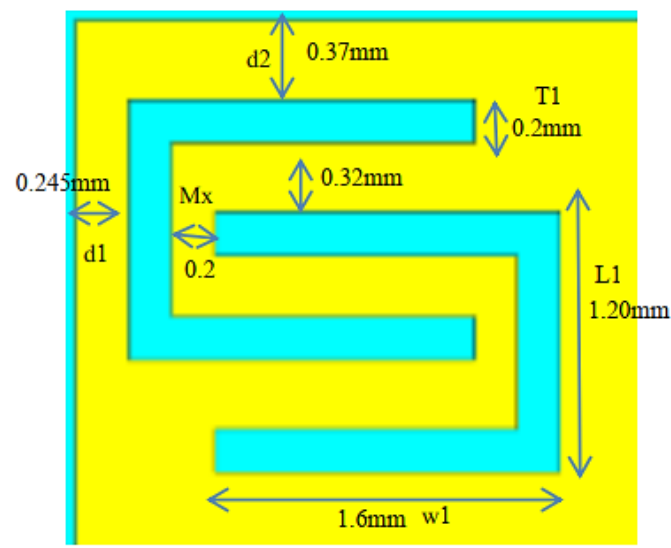

Figure 5: U-shaped slots introduced in patch for dual band peculiarity

Simulations performed on proposed dual band antenna resulted in adequate results in term of return loss, VSWR, gain and directivity both at $28 \mathrm{GHz}$ and $38 \mathrm{GHz}$.

\section{RESUltS AND SimUlations}

(A) Return Loss

For an adequate wireless communication S11 should be less than $-10 \mathrm{~dB}$. The proposed dual band gives a return loss of $32 \mathrm{~dB}$ at $28 \mathrm{GHz}$ and $-40 \mathrm{~dB}$ at $38 \mathrm{GHz}$ respectively. S11 of dual band is depicted in figure 6

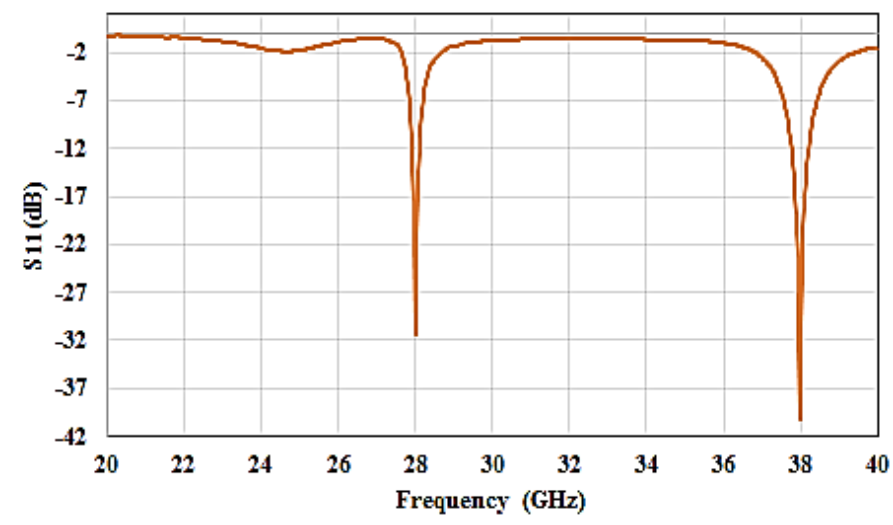

Figure 6: S11 of proposed dual band antenna

\section{(B) Voltage Standing Wave Ratio}

For an ample wireless communication VSWR must be less than 2. The proposed dual band antenna resulted in VSWR in between 1 and 2 at both bands which is quite an acceptable result at higher frequencies. The VSWR of the proposed dual band antenna is projected in figure 7 .

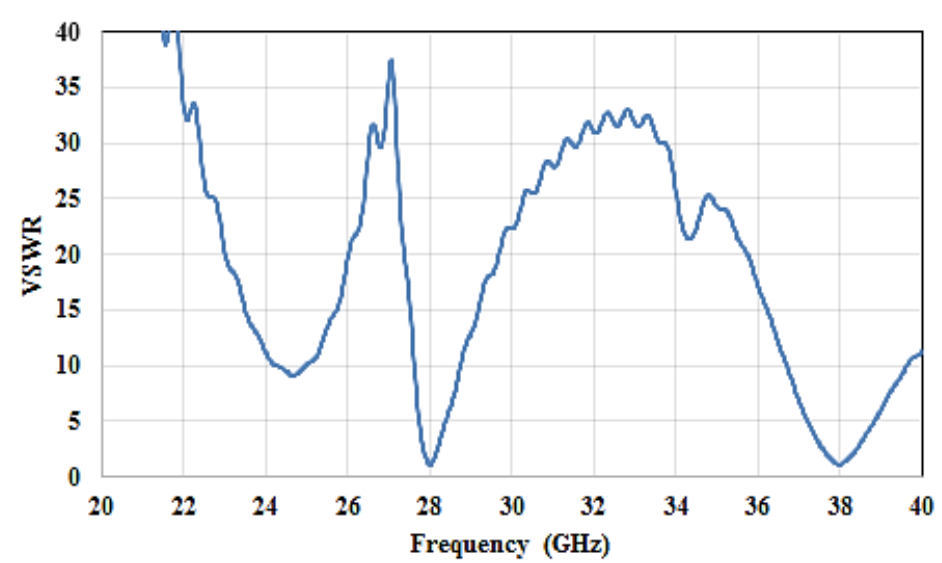

Figure 7: VSWR of proposed dual band antenna

(C) 3-D gain of proposed dual band Antenna

The proposed dual band slotted MPA resulted in a gain of $6.7 \mathrm{~dB}$ at $28 \mathrm{GHz}$ and $7.92 \mathrm{~dB}$ at $38 \mathrm{GHz}$. The $3 \mathrm{D}$ gain at both bands is delineated in figure 8 .

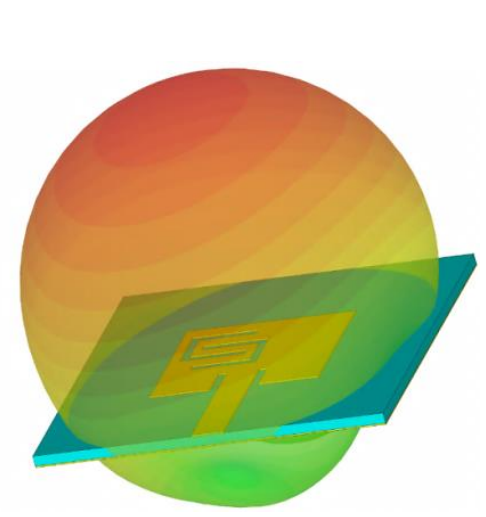

(a) $3 \mathrm{D}$ gain at $28 \mathrm{GHz}$
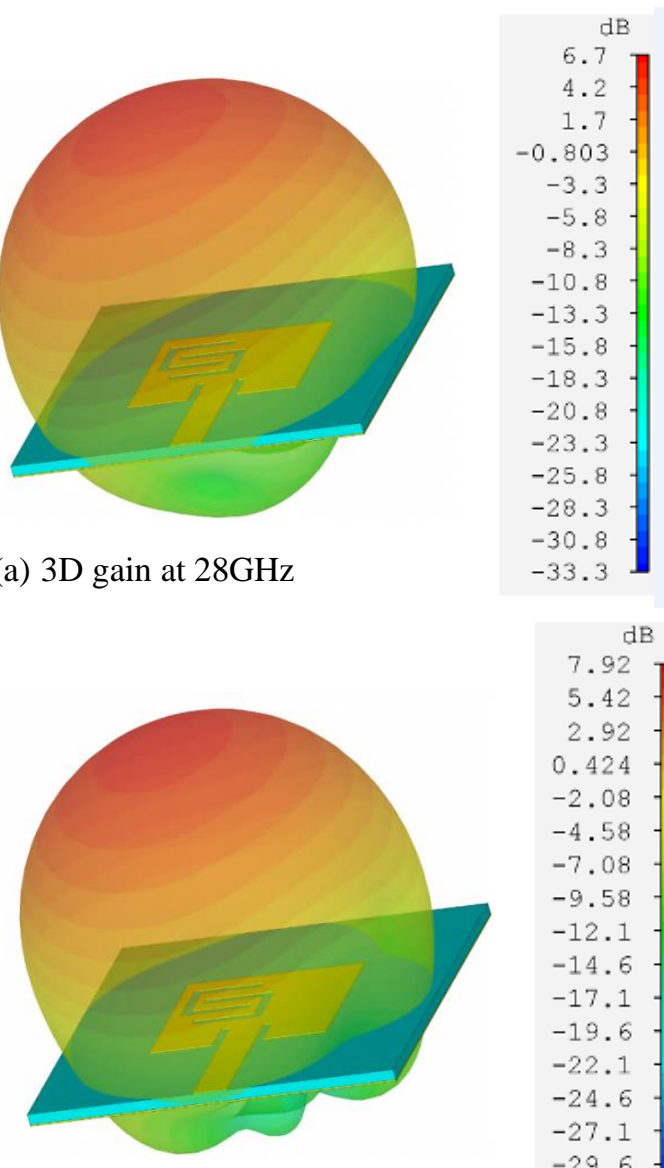

(b) $3 \mathrm{D}$ gain at $38 \mathrm{GHz}$

Figure 8: $3-\mathrm{D}$ gain at $28 \mathrm{GHz}$ and $38 \mathrm{GHz}$ is delineated in this figure.

The gain at both bands in graphical form is depicted in figure 8 . 


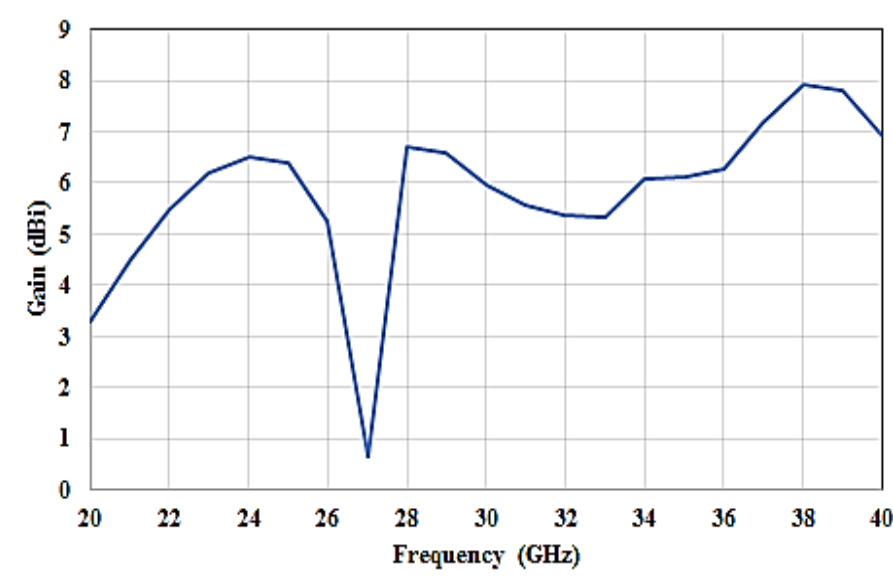

Figure 9: Simulated gain at both bands of proposed dual band antenna

(D) E and H plane of proposed dual band Antenna

The simulated results for $\mathrm{E}$ and $\mathrm{H}$ planes in polar form at both bands are depicted in figure 9.

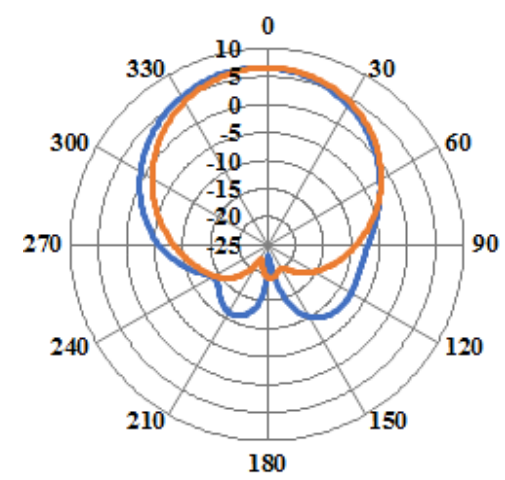

E Plane - H Plane

(a) $\mathrm{E}$ and $\mathrm{H}$ plane at $28 \mathrm{GHz}$

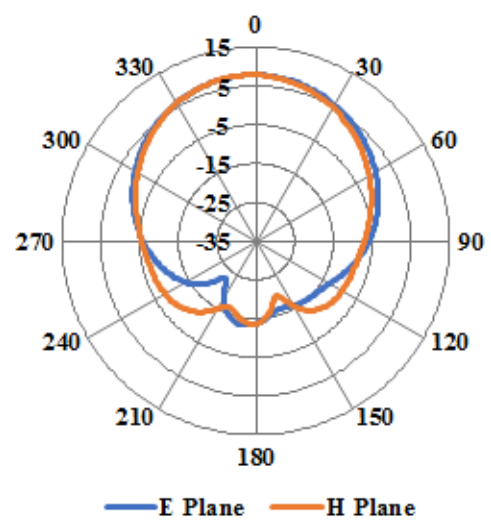

(b) $\mathrm{E}$ and $\mathrm{H}$ plane at $38 \mathrm{GHz}$

Figure 10: E-plane and H-plane at $28 \mathrm{GHz}$ and $38 \mathrm{GHz}$ is depicted in this figure

The results of proposed dual band slotted MPA is delineated in table 3 .
TABLE III RESULTS OF PROPOSED DUAL BAND SLOTTED

\begin{tabular}{|l|c|c|c|}
\hline $\begin{array}{l}\text { Operating } \\
\text { Frequencies }\end{array}$ & S11 & VSWR & Gain \\
\hline $28 \mathrm{GHz}$ & $-32 \mathrm{~dB}$ & $1-2$ & $6.7 \mathrm{~dB}$ \\
\hline $38 \mathrm{GHz}$ & $-40 \mathrm{~dB}$ & $1-2$ & $7.92 \mathrm{~dB}$ \\
\hline
\end{tabular}

\section{V. PARAMETRIC ANALYSIS OF PROPOSED DUAL BAND ANTENNA}

A parametric study carried out on three different antenna parameters to check their impact on performance characteristics of antenna. The first parameter that was altered from its proposed value was patch length $\left(L_{p}\right)$. Patch length was changed from its proposed value $3.27 \mathrm{~mm}$ to $3.17 \mathrm{~mm}$ and $3.37 \mathrm{~mm}$. At $3.27 \mathrm{~mm}$ the antenna gives $\mathrm{S} 11$ of $-32 \mathrm{~dB}$ at $28 \mathrm{GHz}$ and $-40 \mathrm{~dB}$ at $38 \mathrm{GHz}$, when changed to $3.17 \mathrm{~mm}$ from its proposed value, antenna resulted in a return loss of $-22 \mathrm{~dB}$ at $28 \mathrm{GHz}$ and $-27 \mathrm{~dB}$ at $38 \mathrm{GHz}$. At $3.37 \mathrm{~mm}$ patch length antenna resulted in $\mathrm{S} 11$ of $-22 \mathrm{~dB}$ and $-24 \mathrm{~dB}$.

The second parameter that was carried out for parameter study is width of patch element $\left(W_{p}\right)$. The patch width is altered from its $4.09 \mathrm{~mm}$ proposed value to $3.99 \mathrm{~mm}$ and $4.19 \mathrm{~mm}$ respectively. At $4.09 \mathrm{~mm}$ proposed patch width antenna gives $\mathrm{S} 11$ of $-32 \mathrm{~dB}$ at $28 \mathrm{GHz}$ and $-40 \mathrm{~dB}$ at $38 \mathrm{GHz}$ whereas at $3.99 \mathrm{~mm}$ patch width antenna gives $\mathrm{S} 11$ of $-32 \mathrm{~dB}$ at $28 \mathrm{GHz}$ and $-22 \mathrm{~dB}$ at $38 \mathrm{GHz}$ and at $4.19 \mathrm{~mm}$ antenna gives a return loss of $32 \mathrm{~dB}$ at $28 \mathrm{GHz}$ and $-25 \mathrm{~dB}$ at $38 \mathrm{GHz}$. The third parameter which was investigated for parametric analysis is the distance between slots $(\mathrm{Mx})$, the slots distance was altered from its proposed $0.2 \mathrm{~mm}$ value to $0.1 \mathrm{~mm}$ and $0.3 \mathrm{~mm}$. At $0.2 \mathrm{~mm}$ proposed distance antenna gives $-32 \mathrm{~dB} \mathrm{~S} 11$ at $28 \mathrm{GHz}$ and $40 \mathrm{~dB} \mathrm{~S} 11$ at $38 \mathrm{GHz}$, when the distance was changed to $0.1 \mathrm{~mm}$, return loss got changed and at $28 \mathrm{GHz}$ antenna has given an $\mathrm{S} 11$ of $-31 \mathrm{~dB}$ and $-25 \mathrm{~dB}$ at $38 \mathrm{GHz}$ similarly at $0.3 \mathrm{~mm}$ distance $\mathrm{S} 11$ are $-40 \mathrm{~dB}$ at $28 \mathrm{GHz}$ and $-21 \mathrm{~dB}$ at $38 \mathrm{GHz}$ respectively. The parametric analysis of patch length, patch width and distance between slots for S11 is delineated in graphical form in figure 11,12 and 13 .

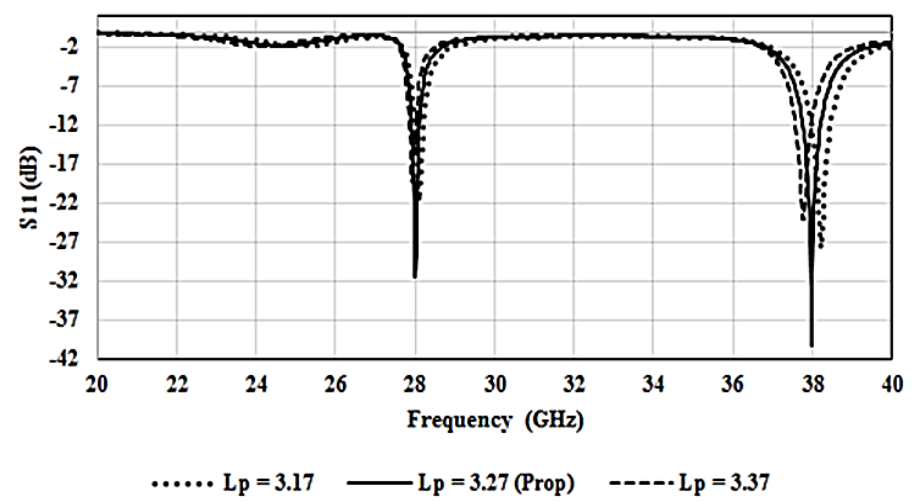

Figure 11: S11 owing to parametric analysis of length of patch element. 


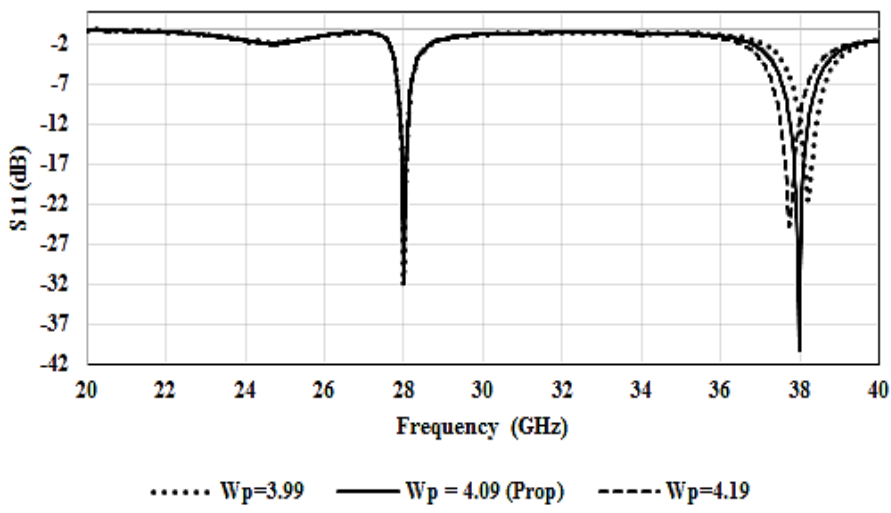

Figure 12: S11 owing to parametric analysis of width of patch element

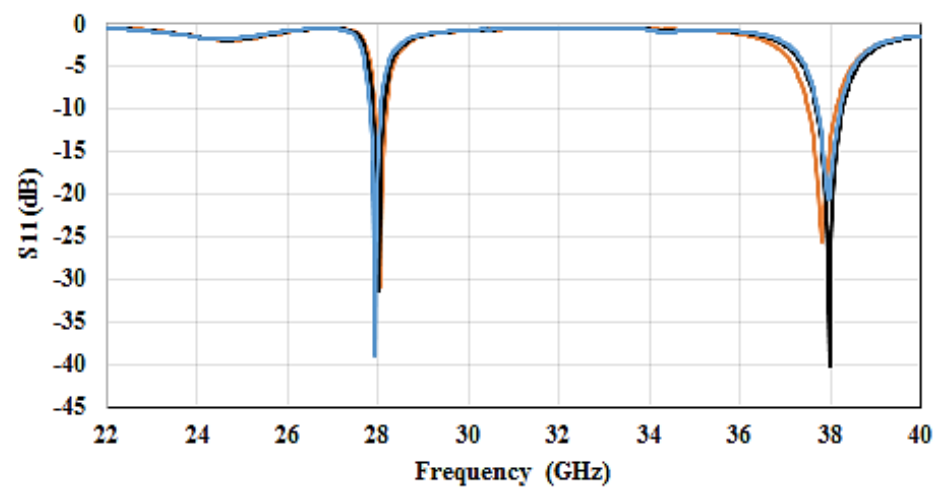

Figure 13: S11 owing to parametric analysis of slots distance

Return loss resulted due to parametric analysis of $L_{p}, W_{p}$ and $M_{x}$ are depicted in table IV.

TABLE IV TABLE COMPRISED S11 RESULTED FROM PARAMETRIC STUDY CONDUCTED ON Lp,Wp AND Mx.

\begin{tabular}{|c|c|c|c|}
\hline Parameters & Values & \multicolumn{2}{|c|}{$\boldsymbol{S}_{\mathbf{1 1}}(\mathbf{d B})$} \\
\cline { 3 - 4 } & & $\mathbf{2 8 G H z}$ & $\mathbf{3 8 G H z}$ \\
\hline$L_{p}$ & $3.27 \mathrm{~mm}$ & -32 & -40 \\
& (proposed) & -22 & -27 \\
& $3.17 \mathrm{~mm}$ & -22 & -24 \\
& $3.37 \mathrm{~mm}$ & & \\
\hline$W_{P}$ & $4.09 \mathrm{~mm}$ & -32 & -40 \\
& (proposed) & -32 & -22 \\
& $3.99 \mathrm{~mm}$ & -32 & -25 \\
& $4.19 \mathrm{~mm}$ & & \\
\hline$M_{x}$ & $0.2 \mathrm{~mm}$ & -32 & -40 \\
& (proposed) & -31 & -25 \\
& $0.1 \mathrm{~mm}$ & -40 & -21 \\
& $0.3 \mathrm{~mm}$ & & \\
\hline
\end{tabular}

\section{CONCLUSION}

A dual band U-shaped slotted Microstrip patch antenna with the peculiarity to operate at two distinct frequency bands i.e. $28 \mathrm{GHz}$ and $38 \mathrm{GHz}$ is delineated in this paper. The design comprised of two stages, in first phase a single band MPA was designed for $28 \mathrm{GHZ}$ band using Rogers RT 5880 substrate, later that antenna was further enhanced to multiband antenna by addition of two U-shaped slots, owing to insertion of slots communication was enabled on two different bands which are $28 \mathrm{GHz}$ and $38 \mathrm{GHz}$. For single band, antenna resulted in $\mathrm{S} 11$ of $-48 \mathrm{~dB}$ at $28 \mathrm{GHz}$ whereas for dual band, antenna resulted in $\mathrm{S} 11$ of $-32 \mathrm{~dB}$ at $28 \mathrm{GHz}$ and $-40 \mathrm{~dB}$ at $38 \mathrm{GHz}$. The VSWR for dual band is in acceptable range. The dual band resulted in an acceptable gain of $6.7 \mathrm{~dB}$ at $28 \mathrm{GHz}$ and $7.92 \mathrm{~dB}$ at $38 \mathrm{GHz}$.

\section{ACKNOWLEDGEMENT}

This research is been carried out in Electrical Engineering Department,UetPeshawar.The author is very thankful to Dr.Irfan khattak for his supervision and unstinting help, the author is also grateful and oblige to antenna research team for their valuable support and guidance.

\section{REFERENCES}

[1] Babu, K. V. and B. Anuradha, "Design of multi-band minkowski MIMO antenna to reduce the mutual coupling," Journal of King Saud UniversityEngineering Sciences, 2018

[2] Ashraf, N., O. M. Haraz, M. M. M. Ali, M. A. Ashraf, and S. A. S. Alshebili, "Optimized broadband and dual-band printed slot antennas for future millimeter wave mobile communication," AEUInternational Journal of Electronics and Communications, Vol. 70, 257-264, 2016

[3] Sulyman, A. I., A. T. Nassar, M. K. Samimi, G. R. MacCartney, T. S. Rappaport, and A. Alsanie,"Radio propagation path loss models for 5G cellular networks in the $28 \mathrm{GHz}$ and $38 \mathrm{GHz}$ millimeterwave bands," IEEE Communications Magazine, Vol. 52, 78-86, 2014.

[4] Islam, M. T., M. N. Shakib, and N. Misran, "Broadband EH shaped microstrip patch antenna for wireless systems," Progress In Electromagnetics Research, Vol. 98, 163-173, 2009.

[5] Hong, W., Z. H. Jiang, C. Yu, J. Zhou, P. Chen, Z. Yu, et al., "Multibeam antenna technologies for 5G wireless communications," IEEE Transactions on Antennas and Propagation, Vol. 65, 6231-6249, 2017.

[6] Khattak, M. I., A. Sohail, U. Khan, Z. Barki, and G. Witjaksono, "Elliptical slot circular patch antenna array with dual band behaviour for future 5G mobile communication networks," Progress In Electromagnetics Research C, Vol. 89, 133-147, 2019.

[7] Kumar, A., A. Q. Ansari, B. K. Kanaujia, J. Kishor, and N. Tewari, "Design of triple-band MIMO antenna with one band-notched characteristic," Progress In Electromagnetics Research C, Vol. 86,41-53, 2018.

[8] Razin Ahmed,Md.Fokhrul Islam, "Slotted Microstrip patch antenna for multiband application." International Electrical Engineering Journal (IEEJ), Vol. 5 (2014) No.3, pp. 1293-1299,ISSN 2078-2365.

[9] Philip Ayiku Dzagbletey, Young-Bae Jung, "Stacked Microstrip Linear Array for Millimeter-Wave 5G Baseband Communication." DO 10.1109/LAWP.2018.2816258, IEEE Antennas and Wireless Propagation Letters

[10] Haraz, O., Ali, M.M.M., Elboushi, A. and Sebak, A.R. (2015) FourElement Dual-Band Printed Slot Antenna Array for the Future 5G Mobile Communication Networks. 2015 IEEE International Symposium on Antennas and Propagation \& USNC/URSI National Radio Science Meeting, Vancouver, 19-24 July 2015, 12.https://doi.org/10.1109/APS.2015.7304386 
[11] Choi, S. H., J. K. Park, S. K. Kim, and J. Y. Park, "A new ultrawideband antenna for UWB applications," Microwave and Optical Technology Letters, Vol. 40, No. 5, March 5, 2004.

[12] Deshmukh, A. A. and G. Kumar, "Formulation of resonance frequency for compact microstrip antennas," IEEE Antennas and Propagation Society International Symposium, 2006.

[13] Kumar. G. and K. C. Gupta, "Broad-band microstrip antennas using additional resonators gap-coupled to the radiating edges," IEEE, Trans. Antennas and Propagate. Vol. 32, 1375-1379, 1994.

[14] D. M. Pozar, "Microstrip Antenna Aperture Coupled to a Microstrip line," Electronics Lett., Vol. 2, pp. 49-50, 1985.

[15] B. Suryakanth and S. N. Mulgi, "Slot loaded rectangular microstrip antennas for multiband operation," World Journal of Science and Technology Vol. 2, No. 10, pp 98-101, 2013

[16] Nishiayama, E. and M. Aikawa, "Wide-band and high gain microstrip antenna with thick parasitic patch substrate," IEEE, Trans. Antennas and Propagate, pp. 273-276, 2004.

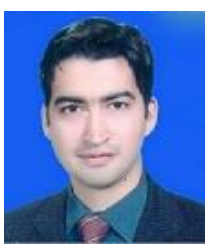

Waqar Hussain:The author belong to district Nowshera,khyberpakhtunkwa pakistan.He did his BS in BEE department from comsats Abbottabad campus and now completed his MS degree in Electrical (communication) Engineering from Uet peshawar. 